\title{
Stress Evaluation of Adhesively Bonded Lap Joints with Aluminum 2024-T3 Adherents Using FEA
}

\author{
M. Khodja ${ }^{1,2, a^{*},}$ A. Ahmed ${ }^{1, b}$, F. Hamida ${ }^{1, c}$, G. Corderley ${ }^{2, d}$ and S. Govender ${ }^{2, e}$
}

${ }^{1}$ LMPM, Mechanics and physics of materials Laboratory, Mechanical Engineering Department, University of Djillali Liabes, Sidi Bel Abbes, BP 98 Cité ben M'Hidi Sidi Bel Abbes 22000, Algeria

${ }^{2}$ CSIR Materials Science and Manufacturing, Meiring Naude Road, Pretoria, 0184, South Africa

a'MKhodja@csir.co.za, ${ }^{a}$ khodja.malika7@gmail.com, bamiri_ahm@yahoo.fr, chamida.fekirini@univ-sba.dz, 'Corderl@csir.co.za, e'SGovender@csir.co.za

Keywords: Adhesive Bonded Joints, Finite element analysis (FEA), Simple-Lap Joint (SLJ), Single Step-Lap Joints (SSLJ), Shear Stresses, Peel Stresses, Von Mises Stresses

\begin{abstract}
The objective of this study is to develop a numerical approach which will lead to a method to aid in the design of bonded assemblies. An AA2024-T3 aluminum alloy was used as adherent for this study with Adekit-140 as the adhesive. The overlapping surfaces of the adherent and the adhesive were modelled with 3D models that were based on surface-to-surface contact elements. Analyses were performed where the length and the thickness of overlap were fixed, keeping the bonding area the same for all geometries. Peel stresses developing at the edges of the overlap area of the adhesively bonded single lap joints subjected to static tensile loading have a profound effect on the damage of the joint. The reduction in the stress values formed at the edges of the overlap area or the transfer of these stresses to the middle part of the overlap area increase the strength of the joint. It was noted that there is symmetry in the stress distribution about the middle of adhesive joint layer according to the length of overlap region. The maximum stresses were at the edge of the bond. Observations have been made on peel and shear stresses in the adhesive layer.
\end{abstract}

\section{Introduction}

Adhesively bonded joints are preferred due to their advantages such as formation of uniform stress distributions, ability to join different materials, high fatigue resistance and impermeability [1]. However, in the adhesively bonded joints, extreme levels of stress concentrations form at the edges of the overlap area, which significantly influences the strength of the joint. In order to use the adhesive bonding technique and to increase the load carrying capacity of the joint, the effect of these stresses forming at the free edges of the bonding area should be reduced. Lap joints, specifically the adhesive single-lap joint, have been studied thoroughly throughout the years. Analytic solutions date back as far as Volkersen [2] and his simplified solution in 1938 that is still more accurate than the current ASTM standards D1002-10 and D3983-98 used to determine the shear strength and shear modulus, respectively. Peel stresses developing at the edges of the overlap area of the adhesively bonded single lap joints subjected to static tensile loading have a profound effect on the damage of the joint. The reduction in the stress values formed at the edges of the overlap area or the transfer of these stresses to the middle part of the overlap area increase the strength of the joint. Results are discussed, followed by numerical work and validation.

\section{Methods}

Several factors need to be considered when designing adhesive joints, notably the peak stresses at the ends of the overlap area and the stresses due to bending moments. It is necessary to be able to determine the state of stress within the joint during the design process in order to achieve the 
correct joint strength. This need necessitated the study of the stress state in a simple adhesive lap joint based on the analytical theories of Volkersen [2] and Goland \& Riesener [3].

\section{Model definition and validation with analytical solution}

Three-dimensional finite element modeling (3D FEM). We consider a lap joints consisting of two aluminum 2024-T3 plates, $\mathrm{E}=68800 \mathrm{MPa}$ joined by an adhesive type ADEKIT A140 [4], $\mathrm{E}=2690 \mathrm{MPa}$ and Shear modulus is $1000 \mathrm{MPa}$ of $0.25 \mathrm{~mm}$ thickness.

The adhesive and adherents are assumed to be linear elastic, homogeneous and isotropic. This adhesive is used in the aeronautical industry and has excellent mechanical and thermal performance up to $100^{\circ} \mathrm{C}$, excellent strength to dynamic loads (vibrations and impacts) and it is adapted to stringent aging and aggressive environments. The dimensions of the various substrates are presented in Fig. 1 which shows the boundary conditions, mechanical properties of material used and the applied nominal stress being $25 \mathrm{MPa}$.

The model of the tapered joint has the same dimensions as the single lap joint. The thickness of the overlapping part is identical to that of the simple overlap, as well as the thickness of the adhesive. To compare the stress distribution, the other adhesive joints was subjected to the same loading as that of the single overlap joint. The thickness of the substrate of the stepped adhesive joint was fixed at $4 \mathrm{~mm}$ as shown in Fig. 1. Finite element analyses of lap joints were performed to calculate stresses in the joints using Abaqus software. The respective patterns of the full finite element meshes of lap joints are shown in Fig. 2. The entire specimen was modelled using an eight node quadrilateral element and the mesh refined in the adhesive layer.
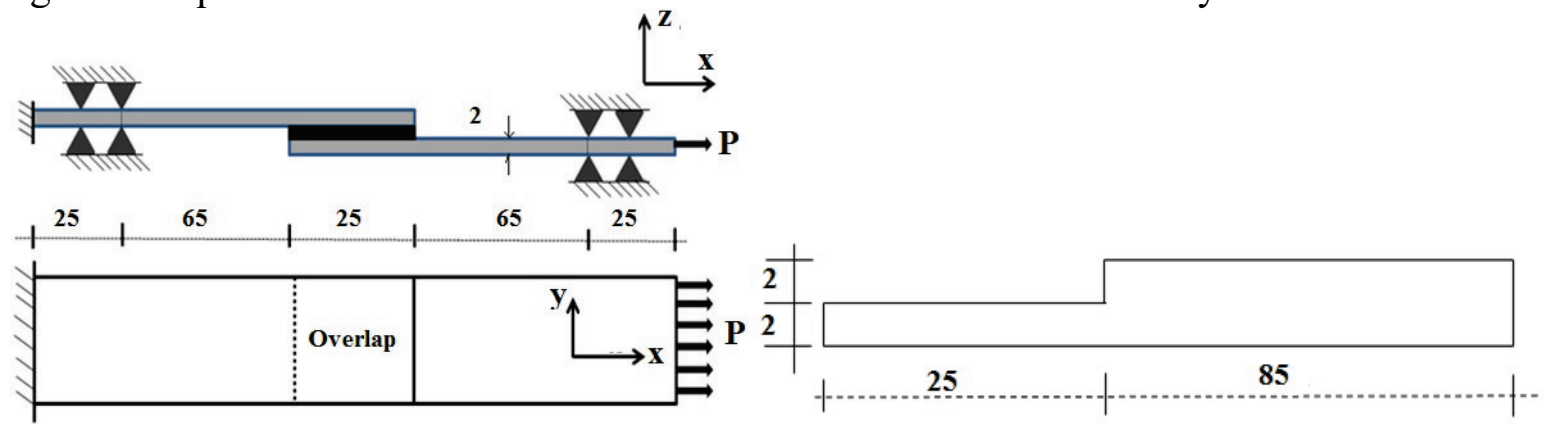

Fig. 1: Single-lap adhesively bonded joint (dimensions in mm) and Dimensions considered for single step-lap adhesively bonded joint.

In the case of analysis of adhesively bonded joints, small elements were used within the adhesive layer and around the adhesive-adherent interfaces and larger elements in the outer regions of the adherents. It is essential to model the adhesive layer with elements which are thinner than the adhesive thickness. The result is that the FE mesh must be several orders of magnitude more refined in every small region than is needed in the rest of the joint. It is also important that a smooth transition between the adherents and adhesive is provided. The finer elements mesh is refined on the two ends of the overlap length.
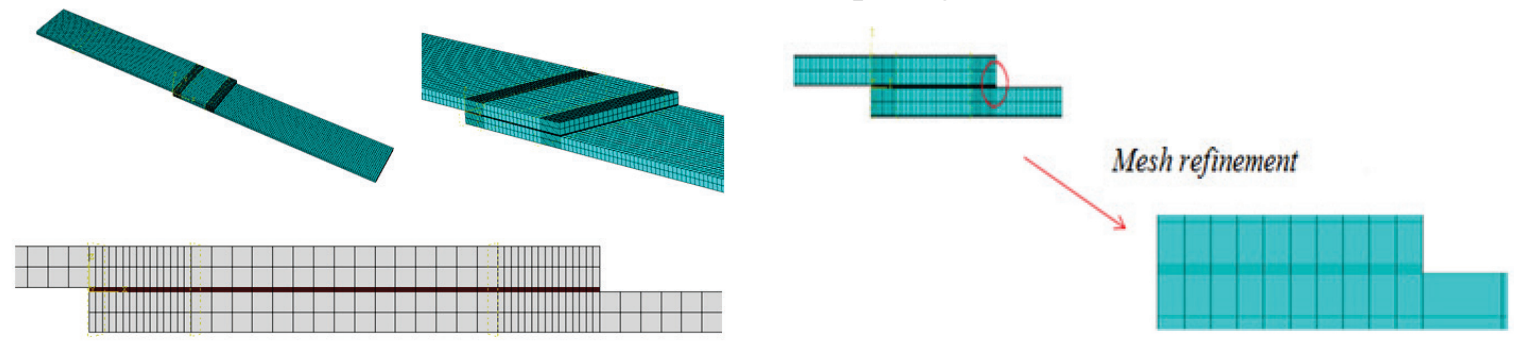

Fig. 2: Typical finite element model and mesh refinement used in lap joint analysis. 
Analytical Evaluation of Stress Components for Simple Lap. Fig. 3 shows the comparison between the analytical method and the finite element method on the peel and shear stresses distribution. The comparison of the two models of Volkersen and Goland \& Reissner for the maximum shear stress shows that the two models behave in a similar way with some variation in the predicted stresses. This variation in the stresses is probably due to the effect of the bending moment induced by the applied loads. The general results show that the analytical and FEA results were in good agreement and proved suitable for single lap joints [5].

Shear stresses « $\tau_{\mathrm{xy}} »$

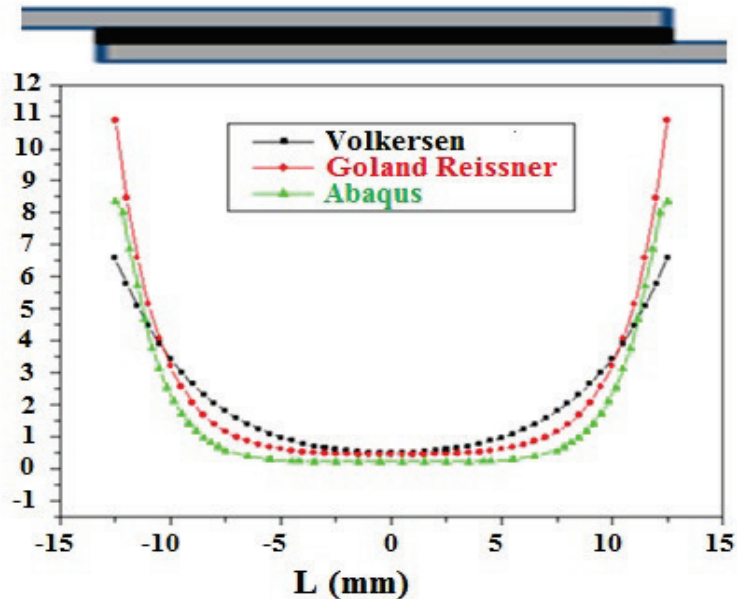

Peel Stress $« \sigma_{y y} »$

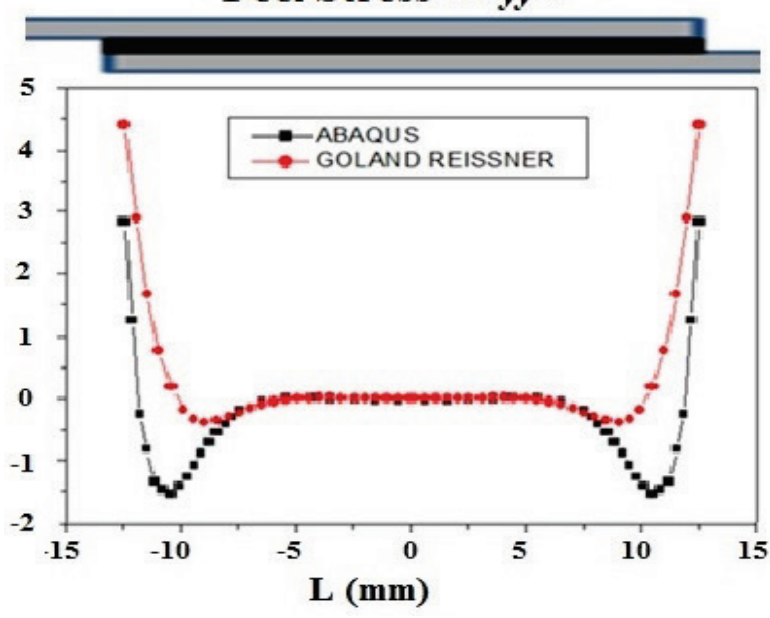

Fig. 3: Comparison between FEM and analytical method on distribution of the adhesive shear and peel stress along the overlap length [5].

\section{Results \& Discussions}

Stress state in the stepped adhesive joint 1 and joint 2. After the analytical results were compared with FEA results using Abaqus [6] and validated, the general results show that the analytical and FEA results were in good agreement and proved suitable for single lap joints [5]. In the case of more complex geometrical configurations, it is impossible to analytically describe the stress field within the adhesive and it is then necessary to use a finite element analysis (FEA) This study covers the behavior of adhesively bonded joints as predicted by FEA. Abaqus has been utilized to investigate the stress distribution along the adhesive layer of three different joint types while under static tensile loading the analysis focused on the central stress of the adhesive joint along line [A-B] in the lap joints modelled as shown in Fig. 4a on simple-lap joint (SLJ), single-steplap joint (joint1) and single-step-lap joint with release at the edges of the bond area (joint2) as shown in Fig. 4b.

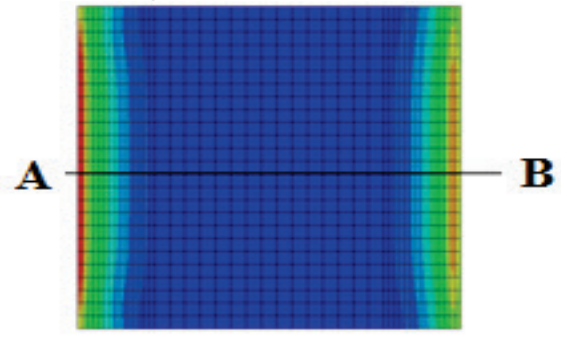

(a)

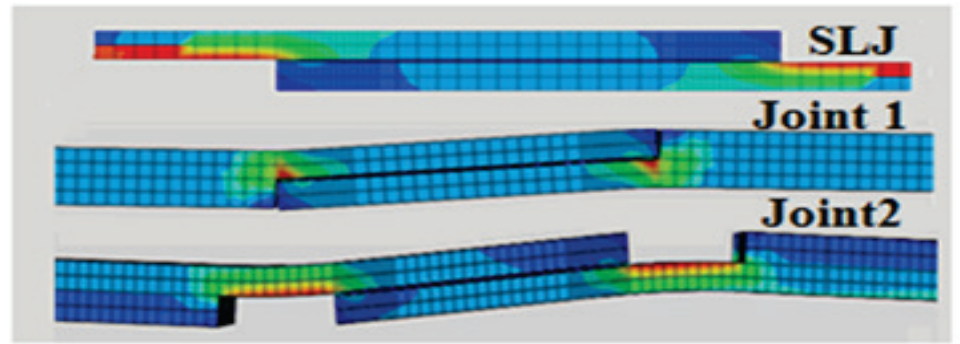

(b)

Fig. 4: (a) The Equivalent Von Mises stress distribution in the adhesive layer; (b) The stress concentration in the region of geometric discontinuity in different lap joints. 
An adhesive joint is characterized by the presence of tensile stress at the ends of the joint, perpendicular to the plane of the adhesive. These peel stresses are caused by the bending of the substrates due to the loading eccentricity, inducing the presence of a bending moment in the joint. In this study, we undertook to investigate a stepped adhesive joint so as to minimize the effect of the bending moment. Fig. 5a shows the geometry of the stepped joint considered. Fig. $5 b$ shows the most important stresses in the joint, Von Mises, $\mathrm{S}_{\mathrm{xx}}(\mathrm{S} 11)$ and $\mathrm{S}_{\mathrm{yy}}(\mathrm{S} 22)$; the stress concentration in the region of geometric discontinuity is evident.

(a)
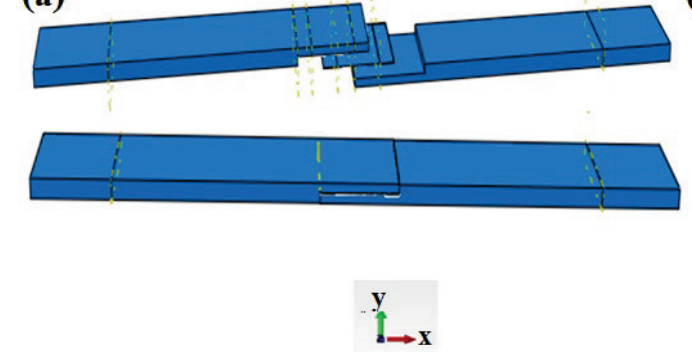

(b)

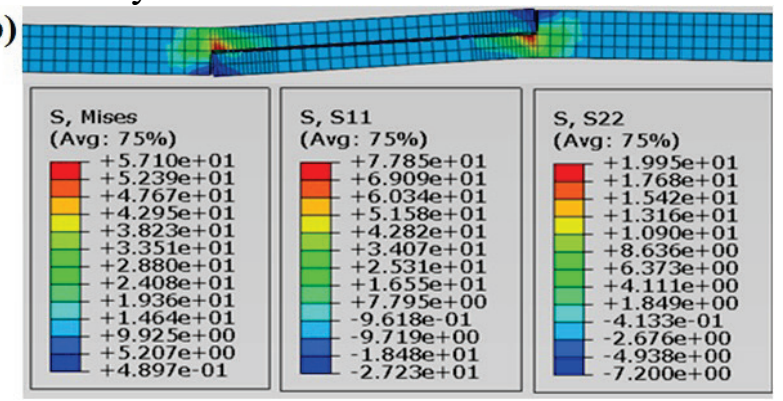

Fig. 5 :(a) Single-Step Lap Joint;(b)Variation of the stress state along the length of overlap joint.

We have noticed that instead of attenuating the stresses in the adhesive, the stepped adhesive joint as defined above does not improve the state of stress with respect to the single-overlap joint. One way to improve the behavior of the stepped adhesive joint would be to release the embedded region, that is, the junction between the overlapped portion and the remainder of the plate. In a stepped adhesive joint the overlapped part of the plate has no free space to flex under the effect of the bending moment. Free edges were allowed so as to release the overlapping portion of the plate, as shown in Fig. 6.

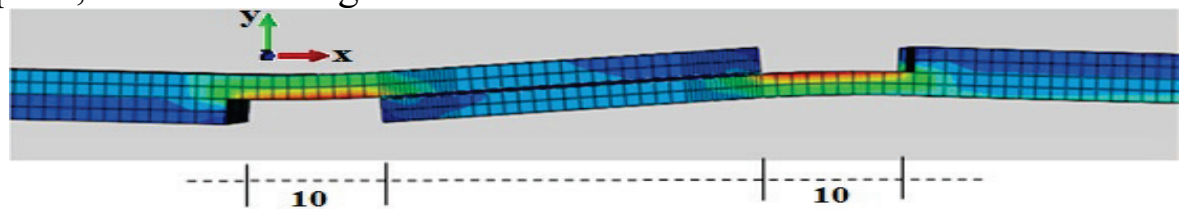

Fig. 6: Single-step joint with release 3D view (joint 2)

Comparison of the stress state in Joint1 and SLJ (single-lap joint). Figure 7 shows the Von Mises stresses, shear stress, peel stresses along the center line of the overlap in a single-lap joint (SLJ) of and the stepped joint (Joint1). The maximum Von Mises stress and shear stress for a stepped adhesive joint is slightly greater than that of the single-layer joint. In the same way as the Von Mises and shear stresses, the same remarks apply for the peeling stresses.

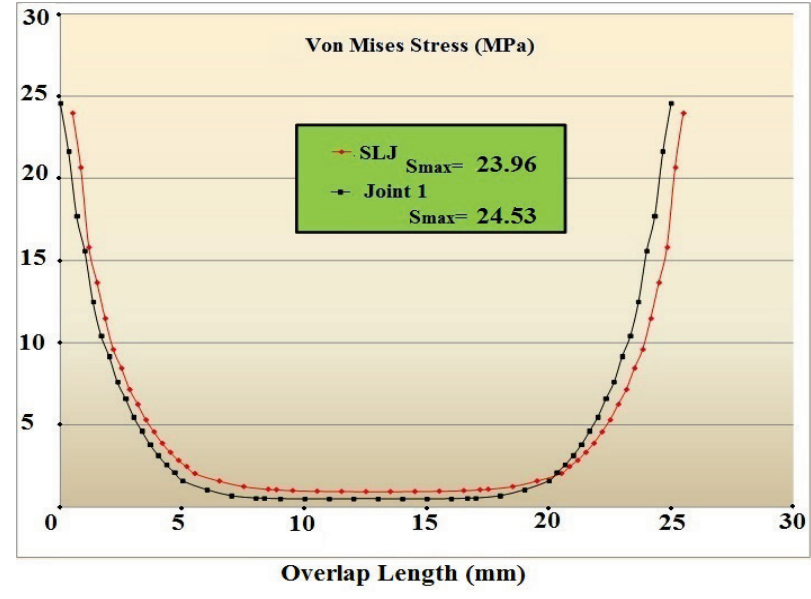

Fig. 7: Comparison of the adhesive Von Mises stress distributions, shear stresses $\tau_{x y}$ and the peel stresses $\sigma_{y y}$ between SLJ and Joint 1 along the overlap length (continue on next page). 

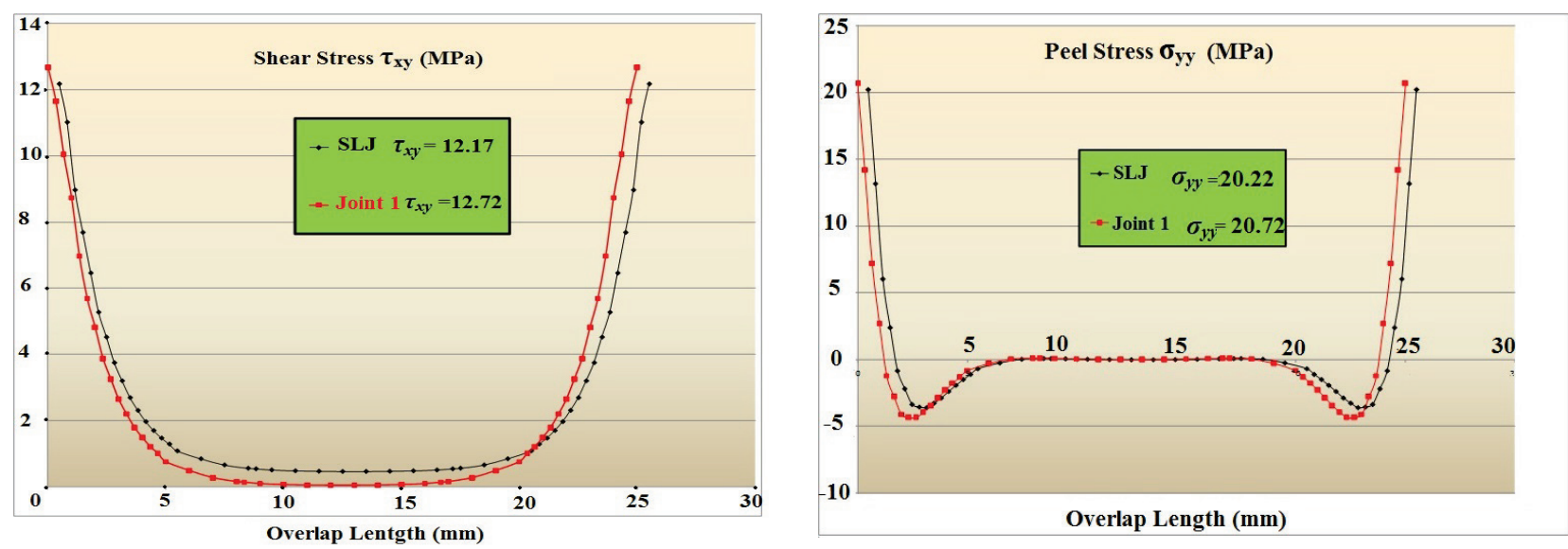

Fig. 7: (Continue from previous page) Comparison of the adhesive Von Mises stress distributions, shear stresses $\tau_{x y}$ and the peel stresses $\sigma_{y y}$ between SLJ and Joint 1 along the overlap length.

Comparison of the stress state in joint 1 , joint 2 and single-lap joint.

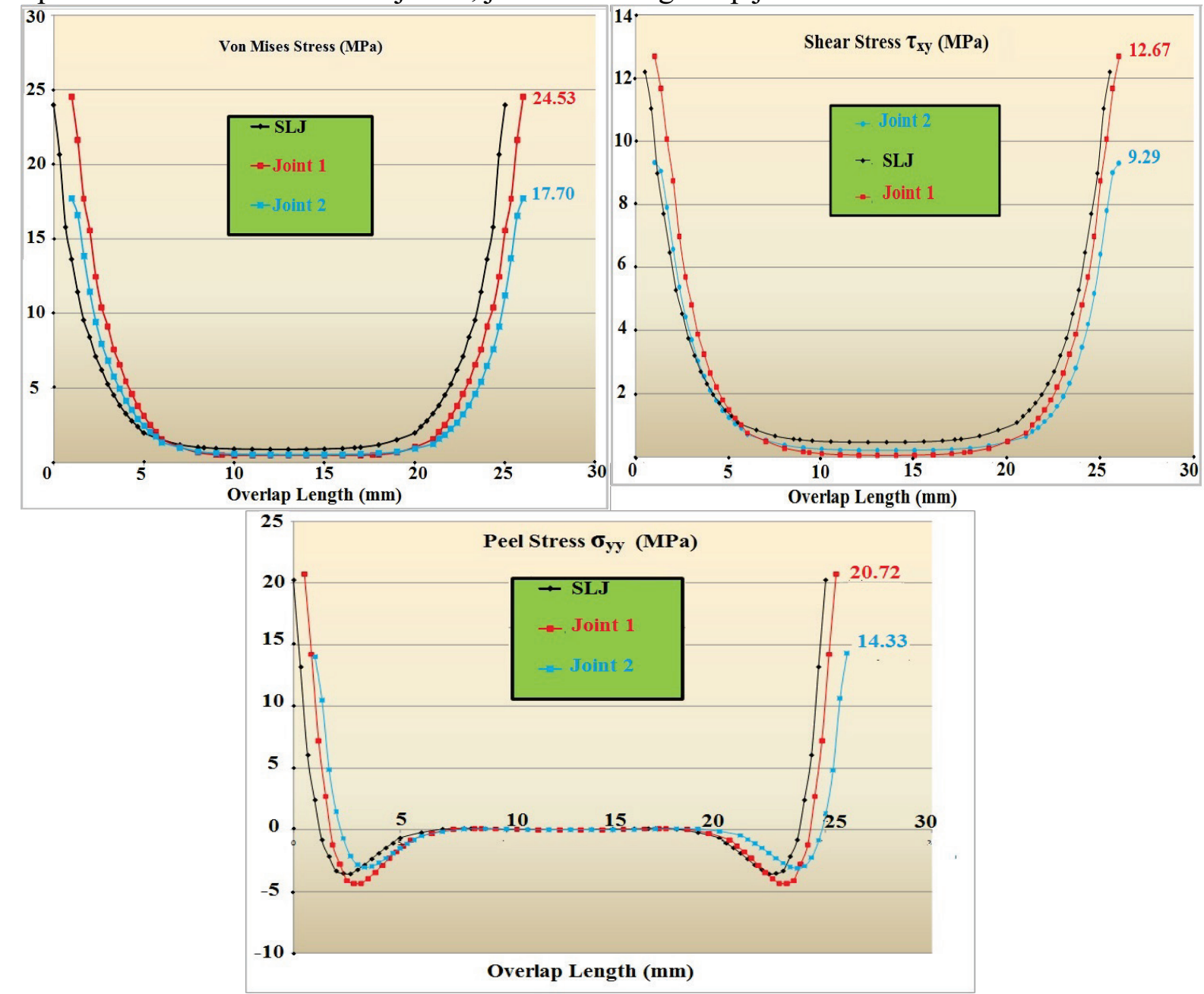

Fig. 8: Variation of the Von Mises stress, shear stress and peel stress distribution along the length of overlap. 
Figure 8 shows that for the adhesive joint with release of the Von Mises stress have decreased by $28 \%$ compared to that of the single-step joint (Joint1). For the released adhesive joint (Joint2) the peeling stress has decreased by $32 \%$ compared to the single-step joint (Joint1) and the shear stress has decreased by $26 \%$ compared with the single-step joint (Joint1).

\section{Conclusions}

In this study, the interfacial adhesive stress distribution of three different joint types, i.e. singlelap joint, single-step lap joint and single-step lap joint with edge release, subjected to tensile loading were investigated numerically by FEM and validated analytically. Accordingly, the following conclusions can be deduced. Good correlation was found between the FEM simulations and the analytical results. The development of a non-linear finite element model approach to simulate the different adhesive joints subjected to static tensile loading has given confidence in the results for bonded assemblies. Changing the geometry of the area in which the bonding process is performed, i.e. using one, two or three steps considering the edge release at the end of bond area has a profound impact on the stress concentrations forming at the adhesive joint and load carrying capacity of the joint. According to the results for the joints having the same bonding area, single-step lap joints with an edge release at bond area the stresses are decreased by about $28 \%$ compared to other joints. The overlap area has a significant effect on the peel and shear stresses. This is due to the geometry of the overlap area which causes a secondary bending in the single lap joint. Designing steps for the adhesively bonded joints at the regions close to the edges of the overlap area decreased the peel stresses at the edges of the overlap area. These peel stresses are effective in initiating damage and this decrease played a significant role in the increase of the joint strength. For the joints, both shear $\left(\tau_{\mathrm{xy}}\right)$ and peel $\left(\sigma_{\mathrm{yy}}\right)$ stress distributions are homogeneous along the width (bond line), while, the distributions have maximum values at the ends along the length and minimum values at the center.

\section{References}

[1] O. Sayman, A. Ozel, A. Pasinli and M. Ozen (2013), Nonlinear stress analysis in adhesively bonded single-lap joint, J. Adhes. Sci. Technol. $27 \quad$ (21)(2013) 2304-2314. https://doi.org/10.1080/01694243.2013.773696

[2] O.Volkersen, Die Niektraftverteilung in Zugbeanspruchten mit Konstanten Laschenquerschritten, Luftfahrtforschung 15 (1938) 41-68.

[3] M. Goland and E. Reissner: The stresses in cemented joints, J. Appl. Mech, ASME, New York, Vol 11, 1944.

[4] K. Madani, S. Touzain, X. Feaugas, S. Cohendouz and M. Ratwani, Experimental and numerical study of repair techniques for panels with geometrical discontinuities, Comput. Mater. Sci. 48 (2010) 83-93. https://doi.org/10.1016/j.commatsci.2009.12.005

[5] M. Khodja, A. Ramdoum, A. Bouakkaz, A. Amiri and W. Oudad, Etude et modélisation d'un joint à simple recouvrement, CNMI 3ème Conférence Nationale de Mécanique et d'Industrie. 3rd, (2014)

[6] Simulia, Dassault Systems. Abaqus software, http://www.3ds.com. Version 6.11, (2011) 